\title{
Current Rates and Symptom Profiles of Panic Disorder in Six Cross-National Studies
}

\author{
*†Myrna M. Weissman. †Glorisa J. Canino. *+Steven Greenwald. \\ \$Peter R. Joyce. \|Elie G. Karam. TChung-Kyoon Lee. \\ $\ddagger$ Maritza Rubio-Stipec. ${ }^{* *}$ J. Elisabeth Wells. \\ $*+$ Priva J. Wickramaratne. and $+\dagger$ Hans-Ulrich Wittchen
}

*Department of Psychiatry. College of Physicians and Surgeons of Columbia L'niversity . X'w Fork: TDivision of Clinical and Genetic Epidemiolog! . Vew York State Psychiatric Institute. Vow York. Now York. L'S..t.: $\ddagger$ Behavioral Sciences Research Institute. Lniversity of Pucroto Ricon. San Juan. Puerto Rico): \$Department of Psychological Wedicine. Christchurch School of Wedicine. Christchurch. New Zealand: \|Deparment of Psychiatry and Psicholog!. Si.

George Hospital and tmerican Liniversity of Beinut. St. Joseph Liniversity, Beinu. Letanom:

'Ke'vo Psichialric Instimte. Kivongii-Do. Korea: ${ }^{* *}$ Deparment of Public Health and General Practice. Christchurch School of Medicine. Christchurch. Ven Zealand:

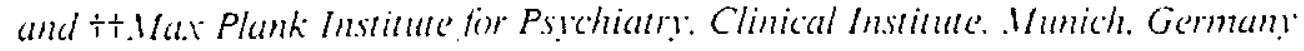

\begin{abstract}
Summary: One-month and 6-month prevalence and symptom profiles of panic disorder from six cross-national epidemiologic studies are reported. These studies were conducted at five sites in the United States. Puerto Rico. Germany. Lebanon. Korea. and New Zealand. Results show that the 1-and 6-month rates were consistent in the five sites in the United States and in other countries. There was a predominance of females in the rates of panic disorder in most countries. Palpitations and trembling were prevalent in $60^{\circ} \mathrm{c}$ or more persons with panic disorder at all sites. The results show that panic disorder is present with similar phenomenology in diverse cultures that have been studied. Key Words: Cross-national psychiatry-Epidemiology-Panic disorder.
\end{abstract}

This is a preliminary report on the cross-national epidemiology of panic disorder. Panic disorder first appeared as a diagnosis in the third edition of the American Psvchiatric Association Diagnostic and Statistical Manual (DSM), published in 1980 (1). and now appears in the recently published International Classification of Disease, 10 th edition (ICD-10) (2). Panic disorder, according to DSM-III, requires at

Address correspondence and reprint requests to Dr. M. M. Weissman at College of Physicians and Surgeons at Columbia University. Division of Clinical and Genetic Epidemiology, New York State Psychiatric Institute. 722 West 168th Street. Unit 14, New York. NY 10032, U.S.A. 
TABLE 1. Specific characteristics of cross-national sites:

\begin{tabular}{ll}
\hline \multicolumn{1}{c}{ Site } & \multicolumn{1}{c}{ Characteristic } \\
\hline U.S. ECA & Five United States sites \\
Puerto Rico & Island of Puerto Rico \\
West Germany & Munich. Germany Follow-up Study \\
Beirut & City of Beirut and its suburbs. Lebanon \\
Korea & Metropolitan Seoul and rural regions \\
New Zealand & City of Christchurch in South Island of New Zealand \\
\hline
\end{tabular}

least three panic attacks in a 3-week period. not solely precipitated by exposure to a specific fearful situation. with any 4 of the following 12 symptoms during an attack: dyspnea. palpitations. chest pain or discomfort. choking or smothering sensations. dizziness. feelings of unreality, paresthesia, hot and cold flashes. sweating, faintness. trembling or shaking. and fear of dying or going crazy. The epidemiology of panic disorder has been well studied in the U.S. NIMH Epidemiologic Catchment Area (ECA) study (3). a large population survey of psychiatric disorders in five U.S. communities. Panic disorder has a lifetime prevalence of $1.5 \%$ in the household sample. is predominant in women compared to men. has high comorbidity with other psychiatric and medical disorders. and carries with it an increase in social morbidity. poor quality of life. and an increased risk for suicide attempts (4-10).

Recently, we formed a cross-national collaboration with investigators who were studying the epidemiology of psychiatric disorders using the same diagnostic and sampling methodologies as the United States ECA during the 1980s. We report here on the 1-and 6-month prevalence and symptom profiles from the United States (3). Puerto Rico (11). Germany (12). Lebanon (13). Korea (14.15). and New Zealand (16.17). Rates and proportions have been standardized to the U.S. household population so that more precise estimates and comparisons can be made.

TABLE 2. One-monih rate/lon. overall and for males and fimales in cross-national sitess aged $18-64^{a}$

\begin{tabular}{lccccc}
\hline & $\begin{array}{c}\text { Number of } \\
\text { subjects }\end{array}$ & Overall & Females & Males & F/M ratio \\
\hline United States & & & & & \\
$\quad$ New Haven. CT & 2.458 & 0.4 & 0.6 & 0.2 & 3.0 \\
Baltimore. MD & 2.558 & 0.8 & 1.1 & 0.4 & 2.7 \\
St. Louis. MO & 2.426 & 0.7 & 0.8 & 0.5 & 1.6 \\
Durham County. NC & 2.680 & 0.6 & 0.9 & 0.3 & 3.0 \\
$\quad$ Los Angeles. CA & 2.745 & 0.6 & 0.8 & 0.4 & 2.0 \\
Puerto Rico & 1.513 & 1.0 & 0.8 & 1.2 & 0.7 \\
West Germany & 481 & 1.2 & 1.6 & 0.8 & 2.0 \\
Beirut & 223 & 1.4 & 1.8 & 1.1 & 1.6 \\
Korea & 5.075 & 1.2 & 2.1 & 0.3 & 7.0 \\
New Zealand & 1.498 & 0.4 & 0.8 & 0.0 & - \\
\hline
\end{tabular}

a All values are standardized to the age and sex distribution of the U.S. ECA. 
TABLE 3. Six-month rate/100, overall and for males and females in cross-national sites, aged $18-64^{a}$

\begin{tabular}{lccccc}
\hline & $\begin{array}{c}\text { Number of } \\
\text { subjects }\end{array}$ & Overall & Females & Males & F/M ratio \\
\hline United States & & & & & \\
$\quad$ New Haven. CT & 2.458 & 0.7 & 1.1 & 0.3 & 3.6 \\
Baltimore. MD & 2.558 & 1.2 & 1.4 & 0.9 & 1.5 \\
St. Louis. MO & 2.426 & 1.0 & 1.2 & 0.8 & 1.5 \\
Durham County. NC & 2.680 & 0.8 & 1.0 & 0.6 & 1.7 \\
Los Angeles. CA & 2.745 & 0.8 & 1.2 & 0.4 & 3.0 \\
Puerto Rico & 1.513 & 1.1 & 0.9 & 1.2 & 0.7 \\
West Germany & 481 & 1.5 & 2.0 & 0.8 & 2.5 \\
Beirut & 223 & 2.1 & 3.1 & 1.1 & 2.8 \\
Korea & 5.075 & 1.4 & 2.2 & 0.4 & 5.5 \\
New Zealand & 1.498 & 1.1 & 1.7 & 0.4 & 4.2 \\
\hline
\end{tabular}

"All values are standardized to the age and sex distribution of the U.S. ECA.

\section{METHOD \\ Description of Cross-National Sites}

Each epidemiologic survey used the Diagnostic Interview Schedule. Version III (18.19) and the DSM-III (1). Each investigator provided data from their studies to be pooled at Columbia University and the New York State Psychiatric Institute. The sites span diverse geographical. political. and cultural areas in North America. the Caribbean. Europe. the Middle East. the Orient. and the Pacific Rim. Table 1 summarizes the specific characteristics of each cross-national site.

\section{Statistical Analysis}

Statistical analyses of these data standardize the rates of panic disorder at each site to the age and sex distribution of the ECA five-site household sample. The ECA was designated as the reference sample because it has the largest sample size and a sampling scheme robust enough to ensure stability of findings. Because the age samplings of the sites differ. analyses are reported only for the 18- to 64-year-old group. with values for Munich based on ages 26 to 64 . The standardization was done according to methods described by Breslow and Day (20). Prevalence rates weighted in this manner give estimates as though each site has the same age and sex distribution of the ECA. Symptom profiles weighted in this manner also reveal estimates as though each site has the same age and sex distribution of the ECA. but take the weighted proportion of persons affected by panic disorder at each site into account.

\section{RESULTS \\ Prevalence and Gender Differences}

The 1-month rate of panic disorder ranges from $0.4 / 100$ in the New Haven site of the ECA and in New Zealand to $1.4 / 100$ in Beirut (Table 2). The rates are consistent across sites and in the five ECA sites. The rates are consistently higher in women compared to men, except for Puerto Rico. The female-to-male ratio in the five sites of 


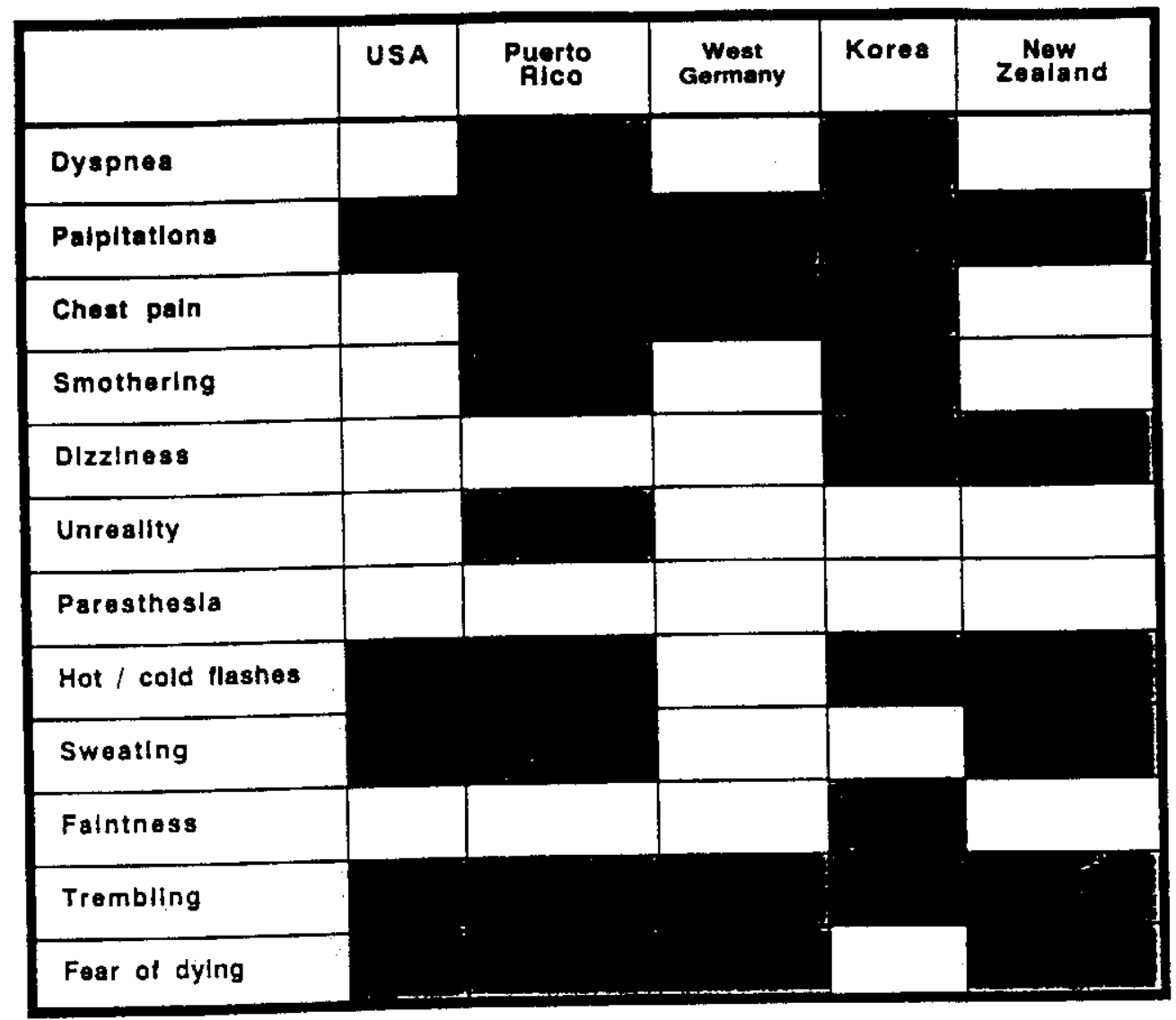

FIG. 1. Symptoms occurring in $60^{\circ} \%$ or more of persons with panic disorder are represented by black boxes by site.

the United States ranges from 1.6:1 at St. Louis to 3.0:1 at New Haven and Durham County. Similar patterns, with slightly higher rates as expected. are seen for the 6-month prevalence (Table 3).

\section{Symptom Profiles}

Symptom profiles in persons with lifetime panic disorder are shown for the crossnational sites in Fig. 1. Symptoms occurring in $60 \%$ or more persons with panic disorder are represented by blackened boxes by site.

Palpitations and trembling were present in $60 \%$ or more of persons with panic disorder at each site. Chest pain, hot and cold flashes, sweating, and fear of dying were also present in $60 \%$ or more of persons with panic disorder at most sites. Feelings of unreality were present in $60 \%$ or more of persons with panic disorder only in Puerto Rico. Paresthesia was present in less than $60 \%$ of persons with panic disorder in each cross-national site.

\section{DISCUSSION}

These results show that panic disorder, as assessed with the Diagnostic Interview Schedule, was present during the past month or past 6 months in the household 
community in diverse cultures studied around the world. Most of the symptoms of panic disorder were present in $60 \%$ or more of persons with panic disorder at most of the sites. suggesting that the phenomenology is similar across sites.

It now remains to investigate further the distribution and determinants of panic disorder. We are undertaking analysis of other risk factors, the association between panic disorder and other psychiatric disorders, and the association with suicide attempts. and will be including data available from other countries. These complete results will be reported in a forthcoming publication.

Acknowledgment: The research reported here derives from a collaborative effor in which each of the authors contributed data from their own studies. Dr. Weissman heads the Cross Vational Collaborative Group. This cross-national reanalysis was supported by grants from the Upjohn Pharmaceutical Company. Kalamazoo. MI. Solvay Pharmaceuticals. Margarietta. GA. and the Vational Institute of Mental Health (MH37592).

\section{REFERENCES}

1. American Psychiatric Association. Committee on Nomenclature and Statistics. Diagnestic and statistical mamul of mental disorders. 3rd ed. Washington. D.C.: American Psychiatric Association. 1980.

2. Incrnatiomal statistical classification of diseases and related heall hroblems. 10th rev. Geneva: World Health Organization. 199?.

3. Robins L.N. Regier DA. eds. Psychicuric disorders in therica: the Epidemiolegic Catchment Area Suchl: New York: The Free Press. 1991.

4. Markowitz JS. Weissman MM. Ouellette R. Lish JD. Klerman GL. Quality of life in panic disorder. Arch (ion Pirchiatry 1989:46:984-9?.

5. Klerman GL. Weissman MM. Ouellette R. Johnson J. Greenwald S. Panic attacks in the community: social morbidity and health care utilization. J.1.1/.4 1991:265:742-6.

6. Eaton WW. Dryman A. Weissman .MM. Panic and phobias. In: Robins L.V. Regier DA. eds. Psichicutric disorders in America: the Enidemiolugic Catchment Area Suld! New York: The Free Press. 1991:155-79.

7. Neugebauer R. Weissman MM. Ouellette R. Markowitz M. Johnson J. Comorbidity of panic disorder and seizures: affinity or artifact. $J$.thx Disord 1992:7:21-35.

8. Weissman WM. Markowitz JS. Ouellette R. Greenwald S. Kahn JP. Panic disorder and cardiovascular/cerebrovascular problems: results from a community surves. .tm J Psichiatry 1990:1 14:1504-8.

9. Lydiard RB. Greenwald S. Weissman MM. Johnson J. Drossman DA. Ballenger JC. Panic disorder and gastrointestinal symptoms: findings from the NIMH-Epidemiologic Catchment Area project. $f m$ $J$ Psichiary 1994:151:64-70.

10. Weissman MM. Klerman GL. Markowitz JS. Ouellette R. Suicide ideation and suicide attempts in panic disorder and attacks. N Engl J . led 1989:321:1209-14.

11. Canino GJ. Bird HR. Shrout PE. et al. The prevalence of specific psychiatric disorders in Puerto Rico. Arch Gen Psychiary 1987:44:727-35.

12. Wittchen HU. Essau CA, von Zerssen D. Krieg JC. Zaudig M. Lifetime and six-month prevalence of mental disorders in the Munich Follow-up Study. Eur .trch Psichiatr. Clin Ninurosci 1992: 241:247-58.

13. Karam E. War events and depression in Lebanon. Presented at a seminar of the International Traumatic Stress Society. Washington. D.C.: October 26. 1991.

14. Lee CK. Kwak YS. Yamamoto J, et al. Psychiatric epidemiology in Korea: Part I: gender and age differences in Seoul. J Ner' Ment Dis 1990:178:242-6.

15. Lee CK. Kwak YS. Yamamoto J. et al. Psychiatric epidemiology in Korea: Part II: urban and rura! differences in Seoul. J Nerv Ment Dis 1990:178:247-52.

16. Wells JE. Bushnell JA. Hornblow AR, Joyce PR. Oakley-Browne MA. Christchurch psychiatric epidemiology study. part I: methodology and lifetime prevalence for specific psychiatric disorders. Alust NZ $J$ Psichiary 1989:23:315-26.

17. Oakley-Browne MA. Joyce PR, Wells JE, Bushnell JA. Hornblow AR. Christchurch psychiatric epide- 
miology study. Part II: six month and other period prevalences for specific psychiatric disorders. ftust NZ J Prichialy 1989:23:327-40.

18. Robins L.V. Helzer JE. Croughan JL. The NIMH diagnostic interview schedule: its history. characteristics. and validity. Arch Gen P.ychiatry 1981:38:381-9.

19. Robins LN. Orvaschel H. Anthony J, Blazer D. Burnam A. Burke J. The diagnostic interview schedule. In: Eaton WW. Kessler LG. eds. Epidemiologic ficld methods in psychiarry: the N7.1/H Eprdcmiologic Catchmont fro'a Program. Orlando. FL: Academic Press. 1985:143-70.

20. Breslow NE. Day NE. Statistical methods in cancer research. Vol. II. The design and analysis of content suthdies. Lyon: International Agency for Research on Cancer. 1987. 